\section{International Scientific Journal Theoretical \& Applied Science}

p-ISSN: 2308-4944 (print) e-ISSN: 2409-0085 (online)

Year: $2018 \quad$ Issue: $06 \quad$ Volume: 62

Published: $26.06 .2018 \quad \underline{\text { http://T-Science.org }}$

SECTION 2. Applied mathematics. Mathematical modeling.
Denis Chemezov

M.Sc.Eng., Corresponding Member of International Academy of Theoretical and Applied Sciences, Lecturer of Vladimir Industrial College, Russian Federation chemezov-da@yandex.ru

Svetlana Tyurina Lecturer of Vladimir Industrial College, Russian Federation swetl.tyurina2015@yandex.ru

Maxim Kulikov Student of Vladimir Industrial College, Russian Federation

Evgeny Bochkarev Student of Vladimir Industrial College, Russian Federation

\title{
A RATIONAL DESIGN OF A HYDRAULIC PACKET CHOKE
}

Abstract: The results of computer simulation of non-Newtonian fluid flow (oil) in packet chokes having a different orifice diameter in a plate and distances between the orifice plates are presented in the article. The information about change of pressure, temperature, dynamic viscosity, vorticity and Prandtl number of moving working fluid at distance from an inlet to an outlet of the packet choke is obtained. It is determined that with increasing of the orifice diameter in the plate and distance between the orifice plates of the packet choke, the process of working fluid flow will be the most stable.

Key words: a packet choke, working fluid, pressure, a model, an orifice, viscosity, vorticity.

Language: English

Citation: Chemezov D, Tyurina S, Kulikov M, Bochkarev E (2018) A RATIONAL DESIGN OF A HYDRAULIC PACKET CHOKE. ISJ Theoretical \& Applied Science, 06 (62): 111-120.

Soi: http://s-o-i.org/1.1/TAS-06-62-21 Doi: crossef https://dx.doi.org/10.15863/TAS.2018.06.62.21

\section{Introduction}

A hydraulic choke is a hydraulic resistance. This device establishes a certain connection between fluid pressure drop on the choke and flow rate through it.

The packet choke consists of the several hydraulic resistances (orifice plates) which are set in a case. Distance between the orifice plates should be $l=3 d \ldots 5 d$ (where $d$ is an orifice diameter in the plate, $\mathrm{mm}$ ). The orifice diameter in the plates is taken not less than $0.5 \mathrm{~mm}$. The orifice plate thickness is determined by the formula $\delta=0.4 d \ldots 0.5 d$. This hydraulic choke has high hydraulic resistance and stable flow characteristics.

Flow is repeatedly narrowed and expanded when fluid flow through the orifice plates of the packet choke. This leads to fluid pressure drop in sections of the packet choke. Herewith, the diameter reduction of the orifice in the plates leads to increasing of fluid pressure at an inlet, and the diameter increasing of the orifice in the plates leads to increasing of the packet choke length. By means of computer simulation it is possible to determine hydraulic parameters of fluid flow, and thus to choose a rational design of the packet choke.

\section{Materials and methods}

Computer simulation of working fluid flow in the packet chokes was performed in the special program Flow Simulation [1].

Three three-dimensional solid models of the packet chokes were created for implementation of computer simulation (the Fig. 1). The packet chokes models had the different internal design. The sections number in each model of the packet choke was taken 8. The orifice plates of the packet chokes were located staggered. Main dimensions of the packet chokes models are presented in the table 1. The constant dimensions of the packet chokes were: the diameters of the inlet and the outlet $-12 \mathrm{~mm}$ and a width of each orifice plate $-20 \mathrm{~mm}$. A height of the orifice plate was taken $40 \mathrm{~mm}$. 


\begin{tabular}{l|lr|ll|ll} 
& ISRA (India) & $=\mathbf{1 . 3 4 4}$ & SIS (USA) & $=\mathbf{0 . 9 1 2}$ & ICV (Poland) & $=\mathbf{6 . 6 3 0}$ \\
Impact Factor: & ISI (Dubai, UAE) & $=\mathbf{0 . 8 2 9}$ & PUHЦ (Russia) & $=\mathbf{0 . 2 0 7}$ & PIF (India) & $=1.940$ \\
& GIF (Australia) & $=\mathbf{0 . 5 6 4}$ & ESJI (KZ) & $=4.102$ & IBI (India) & $=\mathbf{4 . 2 6 0}$ \\
& JIF & $=\mathbf{1 . 5 0 0}$ & SJIF (Morocco) $=\mathbf{2 . 0 3 1}$ & & \\
\hline
\end{tabular}

A

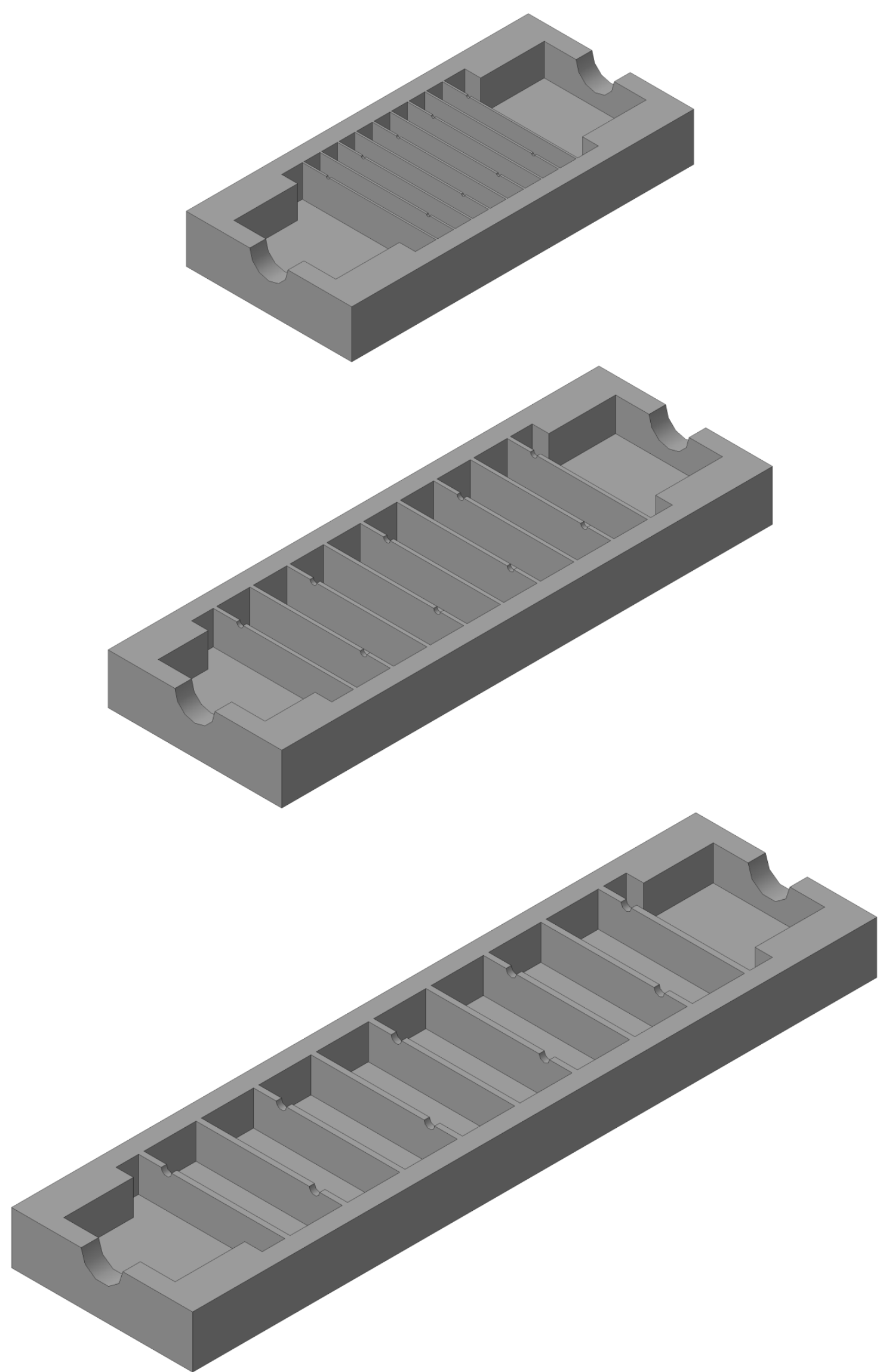

B

Figure 1 - The first (A), the second (B) and the third (C) solid models of the packet chokes in the longitudinal section. 


\begin{tabular}{l|lr|ll|ll} 
& ISRA (India) & $=\mathbf{1 . 3 4 4}$ & SIS (USA) & $=\mathbf{0 . 9 1 2}$ & ICV (Poland) & $=\mathbf{6 . 6 3 0}$ \\
Impact Factor: & ISI (Dubai, UAE) $=\mathbf{0 . 8 2 9}$ & PUHЦ (Russia) $=\mathbf{0 . 2 0 7}$ & PIF (India) & $=\mathbf{1 . 9 4 0}$ \\
& GIF (Australia) & $\mathbf{0 . 5 6 4}$ & ESJI (KZ) & $=\mathbf{4 . 1 0 2}$ & IBI (India) & $=\mathbf{4 . 2 6 0}$ \\
& JIF & $=\mathbf{1 . 5 0 0}$ & SJIF (Morocco) & $=\mathbf{2 . 0 3 1}$ & & \\
\hline
\end{tabular}

Main dimensions of the packet chokes models.

Table 1

\begin{tabular}{|c|c|c|c|}
\hline \multirow{2}{*}{ Parameter } & \multicolumn{3}{|c|}{ Value (in mm) } \\
\cline { 2 - 4 } & The first model & The second model & The third model \\
\hline Orifice diameter in the plate, $d$ & 1 & 2 & 3 \\
\hline Distance between orifice plates, $l$ & 5 & 10 & 15 \\
\hline Orifice plate thickness, $s$ & 0.5 & 1 & 1.5 \\
\hline
\end{tabular}

Oil (non-Newtonian fluid) was moved under pressure in the sections of the packet chokes models [2 - 4]. Working fluid at temperature of $293.2 \mathrm{~K}$ flows in the inlet of the packet choke at a velocity of $0.5 \mathrm{~m} / \mathrm{s}$. Working fluid outflows under static pressure of $101325 \mathrm{~Pa}$ from the outlet of the packet choke. The following properties were adopted for working fluid: density $-917.53 \mathrm{~kg} / \mathrm{m}^{3}$, specific heat -1971.8 $\mathrm{J} /(\mathrm{kg} \times \mathrm{K})$, thermal conductivity $-0.17 \mathrm{~W} /(\mathrm{m} \times \mathrm{K})$. Viscosity of working fluid was calculated by powerlaw model [5-6]. Power-law index was taken 1 . The dependence of consistency coefficient from temperature is presented in the Fig. 2.

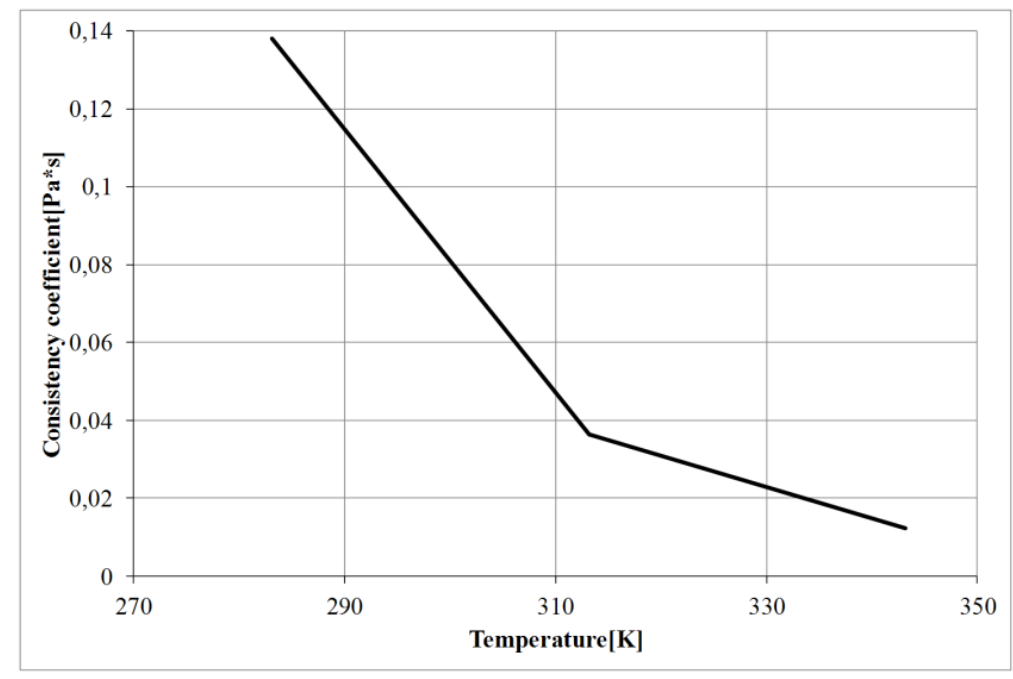

Figure 2 - The dependence of consistency coefficient from temperature.

Iron was accepted by material of the packet choke. Initial temperature of material of the packet choke was taken $293.2 \mathrm{~K}$. The following parameters were set for internal surfaces of the packet choke: walls roughness $-5 \mu \mathrm{m}$, wall radiative surface black body [7], specularity coefficient -0 , emissivity coefficient -1 , solar absorptance -1 . The ratio of finite elements of the solid model (the choke) to finite elements of the working fluid model is 1:10. This says about a high quality of the simulation results of working fluid flow in the packet choke.

\section{Results and discussion}

The results of computer simulation are presented in a form of color plots characterizing a change of the some hydraulic parameters of working fluid when moving in the packet choke model.

Trajectory of working fluid flow in the packet chokes models is presented by color lines. Working fluid pressure in the models of the packet chokes is presented in the Fig. 3.
Working fluid pressure at the inlet of three models of the packet chokes is different. At that in the first model of the packet choke, working fluid pressure is maximum in value, in the third model is minimum pressure. Working fluid pressure at the inlet decreases with increasing distance between the orifice plates and the orifice diameter in the plates of the packet choke.

The first model of the packet choke is irrational, because for creation of working fluid static pressure at the outlet, high pressure of working fluid at the inlet (approximately $441 \mathrm{MPa}$ ) is required. This high pressure contributes to damage of the plates in the design of the packet choke. From the presented models of the packet chokes it is preferable to use the third model, since pressure drop of working fluid from the section to the section is not more than 0.1 $\mathrm{MPa}$.

Working fluid temperature in the models of the packet chokes is presented in the Fig. 4. 


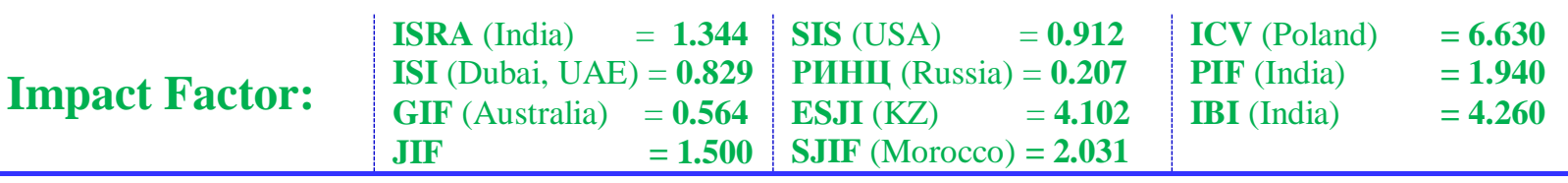

A
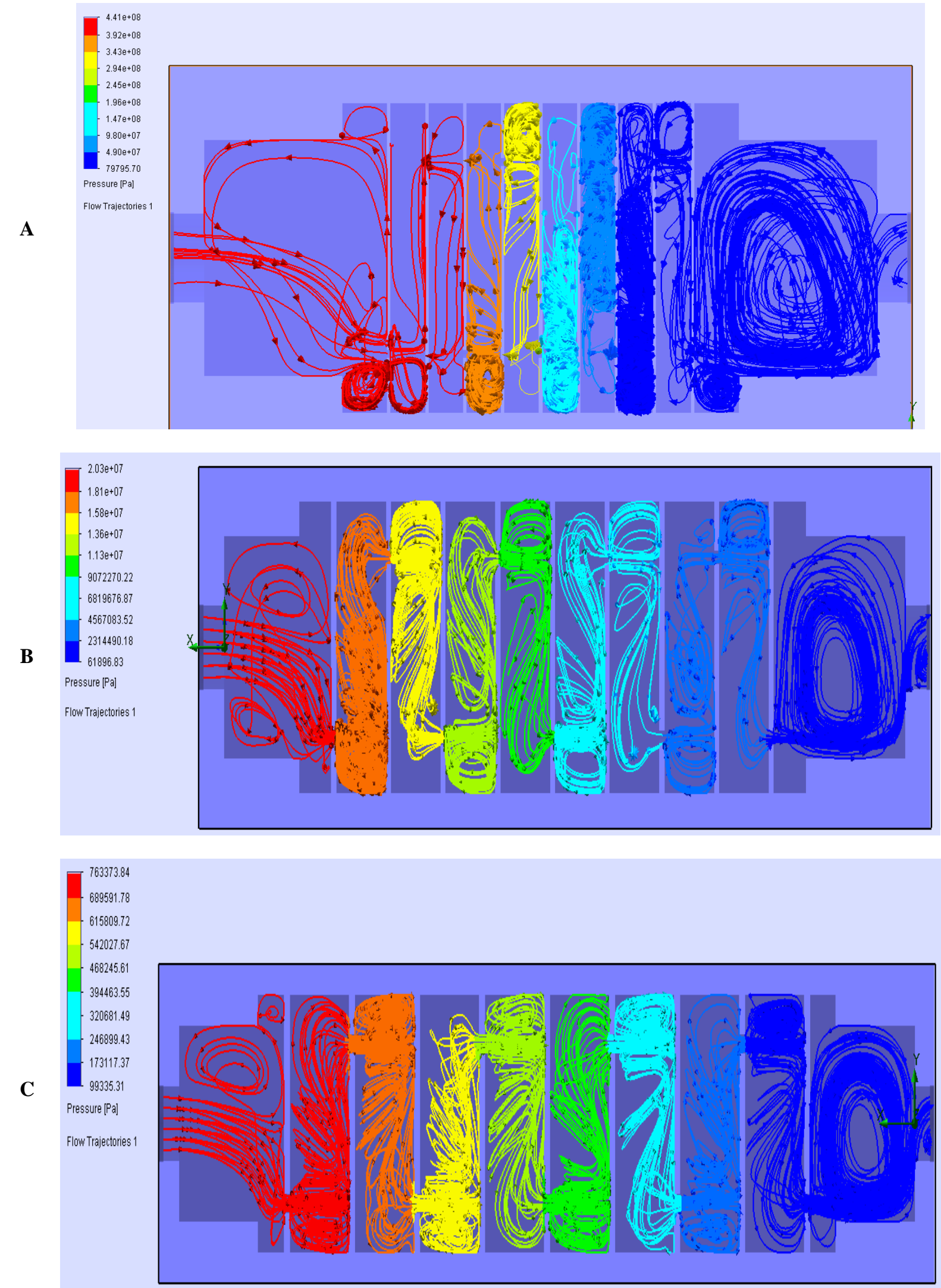

Figure 3 - Working fluid pressure in the first (A), the second (B) and the third (C) models of the packet chokes. The orifice of the packet choke on the left is the inlet (and further), the orifice of the packet choke on the right is the outlet (and further). 


\begin{tabular}{|c|c|c|c|c|c|c|}
\hline \multirow{4}{*}{ Impact Factor: } & ISRA (India) & $=1.344$ & SIS (USA) & $=0.912$ & \multirow{4}{*}{$\begin{array}{l}\text { ICV (Poland) } \\
\text { PIF (India) } \\
\text { IBI (India) }\end{array}$} & \multirow{4}{*}{$\begin{array}{l}=6.630 \\
=1.940 \\
=4.260\end{array}$} \\
\hline & ISI (Dubai, UAE & $=0.829$ & РИНЦ (Russia) & $=0.207$ & & \\
\hline & GIF (Australia) & $=0.564$ & ESJI (KZ) & $=4.102$ & & \\
\hline & JIF & $=1.500$ & SJIF (Morocco & $=\mathbf{2 . 0 3 1}$ & & \\
\hline
\end{tabular}

A
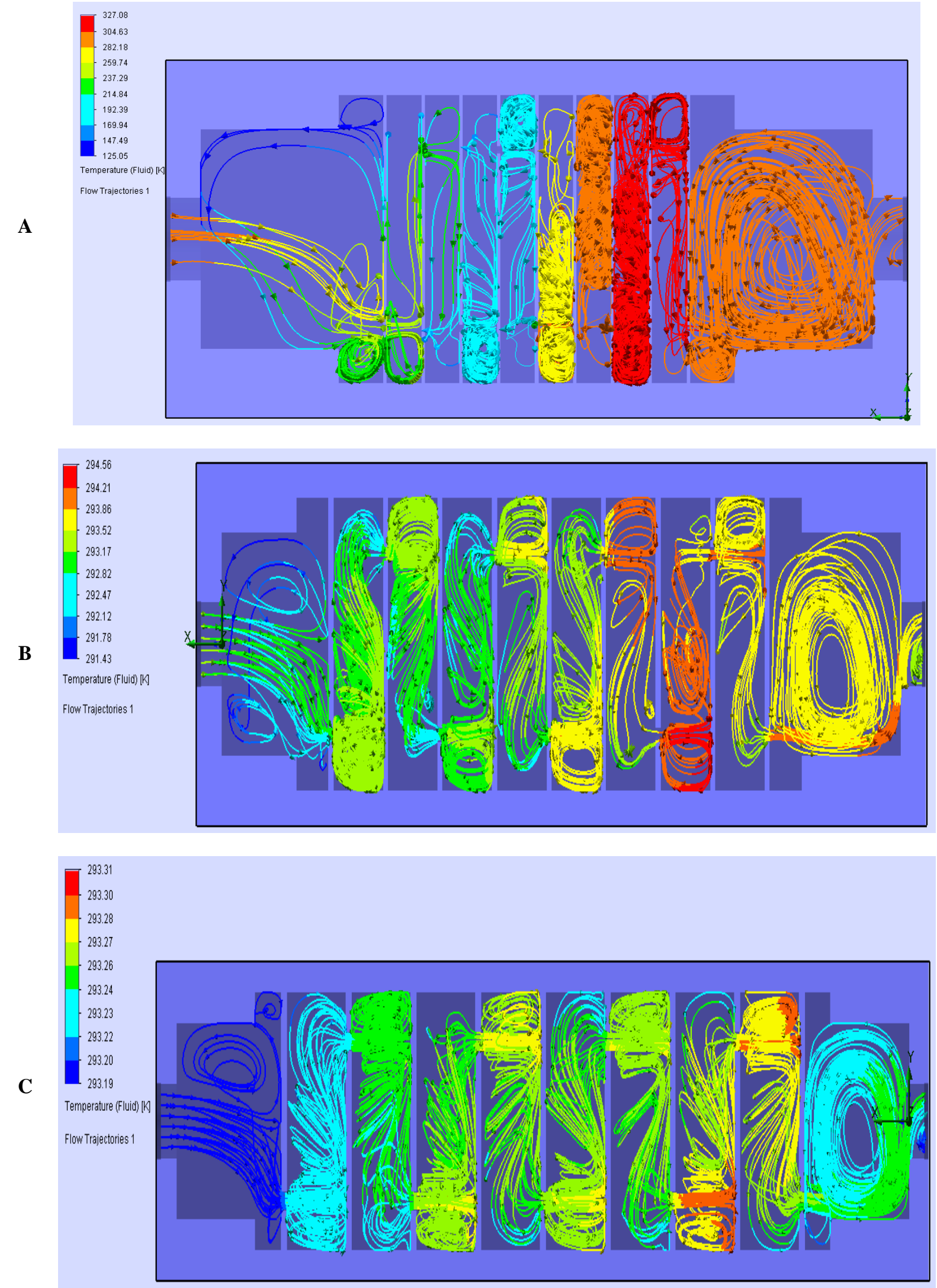

Figure 4 - Working fluid temperature in the first (A), the second (B) and the third (C) models of the packet chokes. 


\begin{tabular}{|c|c|c|c|c|c|c|}
\hline \multirow{4}{*}{ Impact Factor: } & ISRA (India) & $=1.344$ & SIS (USA) & $=0.912$ & \multirow{4}{*}{$\begin{array}{l}\text { ICV (Poland) } \\
\text { PIF (India) } \\
\text { IBI (India) }\end{array}$} & \multirow{4}{*}{$\begin{array}{l}=6.630 \\
=1.940 \\
=4.260\end{array}$} \\
\hline & ISI (Dubai, UAE & $=0.829$ & РИНЦ (Russia) & $=0.207$ & & \\
\hline & GIF (Australia) & $=0.564$ & ESJI (KZ) & $=4.102$ & & \\
\hline & JIF & $=1.500$ & SJIF (Morocco & $=\mathbf{2 . 0 3 1}$ & & \\
\hline
\end{tabular}

A
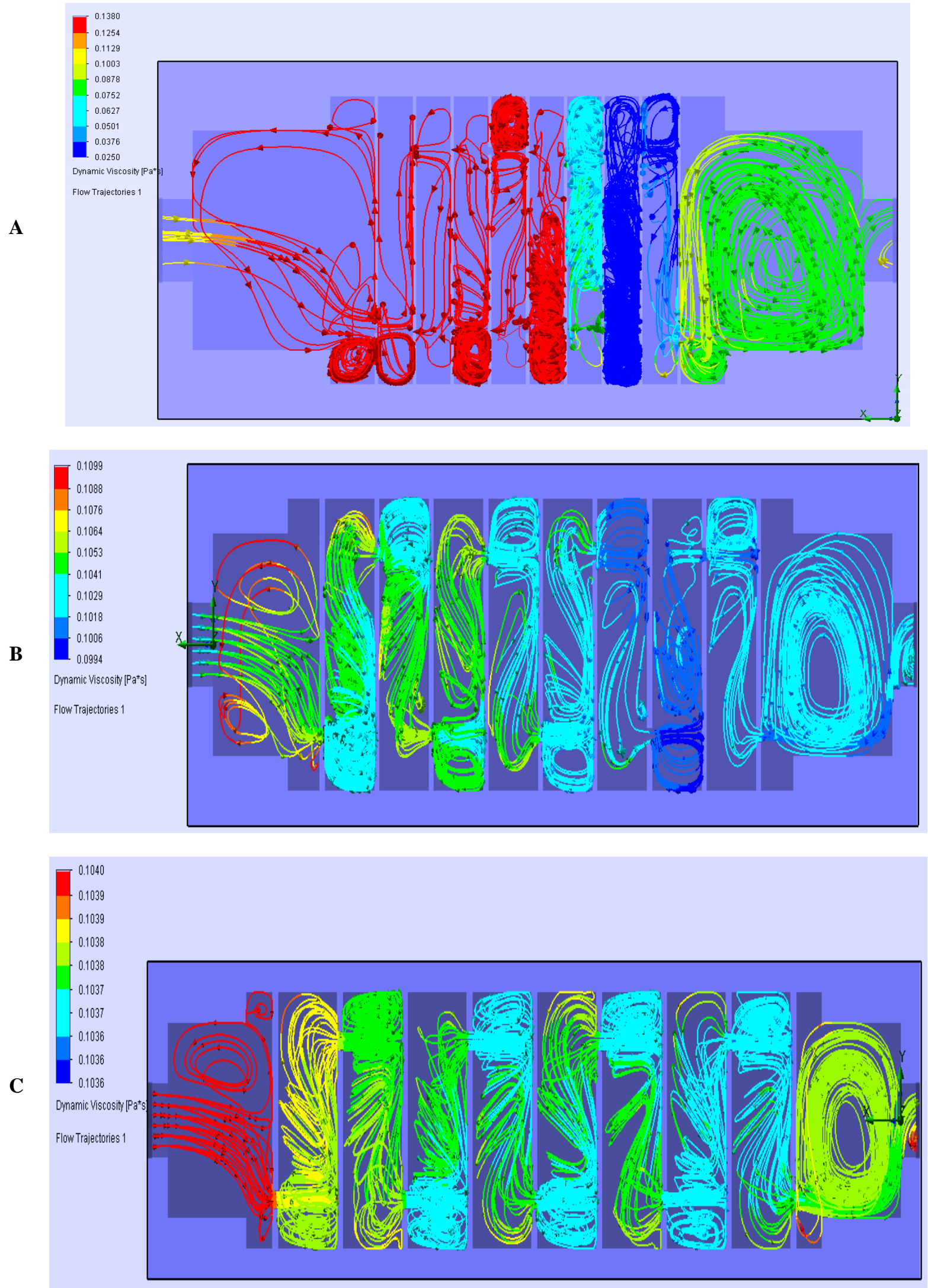

Figure 5 - Dynamic viscosity of working fluid in the first (A), the second (B) and the third (C) models of the packet chokes. 


\begin{tabular}{|c|c|c|c|c|c|c|}
\hline \multirow{4}{*}{ Impact Factor: } & ISRA (India) & $=1.344$ & SIS (USA) & $=0.912$ & ICV (Poland) & $=6.630$ \\
\hline & ISI (Dubai, UAE & $=0.829$ & РИНЦ (Russia) & $=0.207$ & PIF (India) & $=1.940$ \\
\hline & GIF (Australia) & $=0.564$ & ESJI (KZ) & $=4.102$ & IBI (India) & $=4.260$ \\
\hline & JIF & $=1.500$ & SJIF (Morocco & $=2.031$ & & \\
\hline
\end{tabular}

A
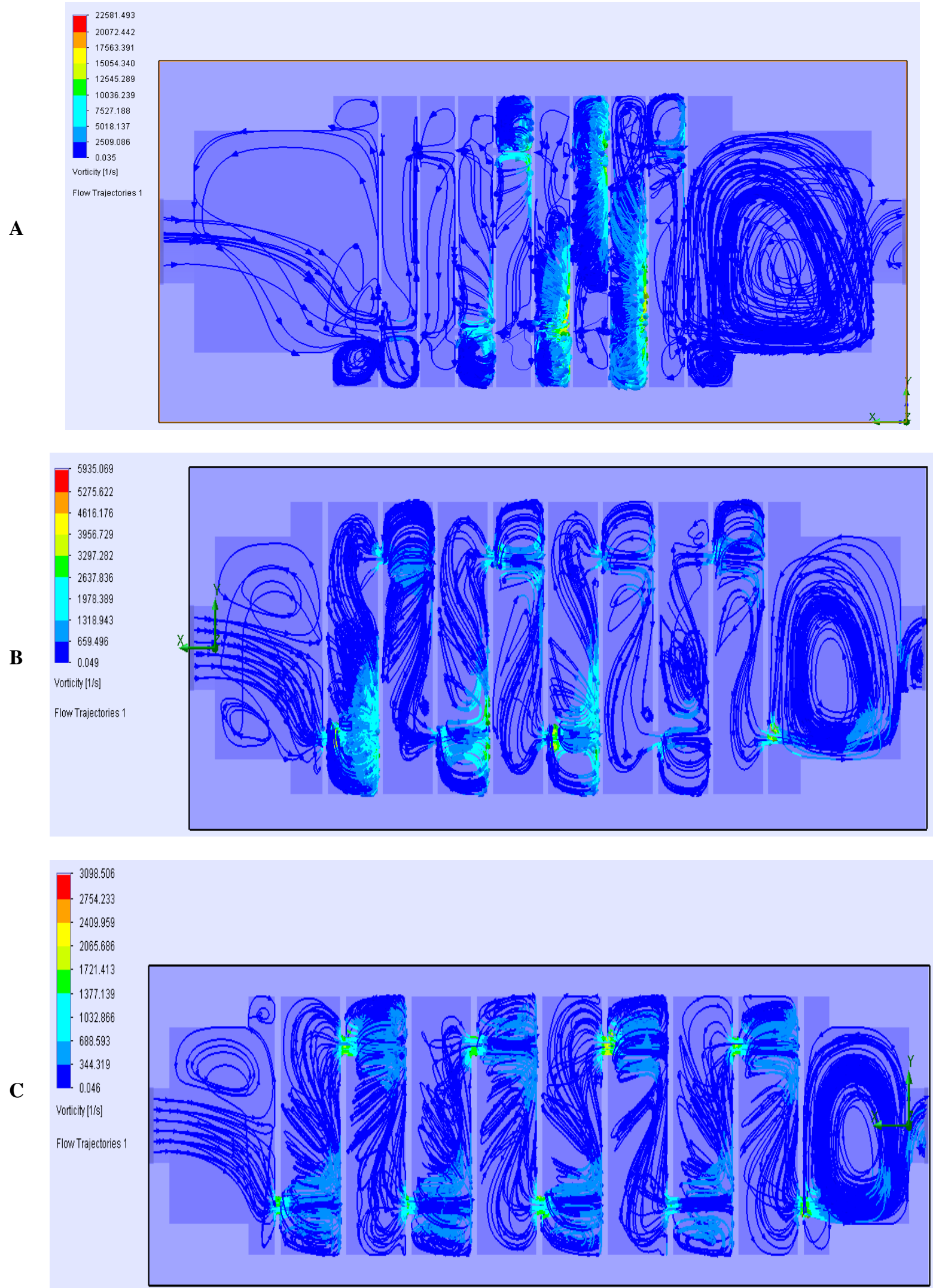

Figure 6 - Working fluid vorticity in the first (A), the second (B) and the third (C) models of the packet chokes. 


\begin{tabular}{|c|c|c|c|c|c|c|}
\hline \multirow{3}{*}{ Impact Factor: } & ISRA (India) & $=1.344$ & SIS (USA) & $=0.912$ & ICV (Poland) & $=6.630$ \\
\hline & ISI (Dubai, UAE & $=0.829$ & РИНЦ (Russia) & $=0.207$ & PIF (India) & $=1.940$ \\
\hline & GIF (Australia) & $=0.564$ & ESJI (KZ) & $=4.102$ & IBI (India) & $=4.260$ \\
\hline
\end{tabular}

A
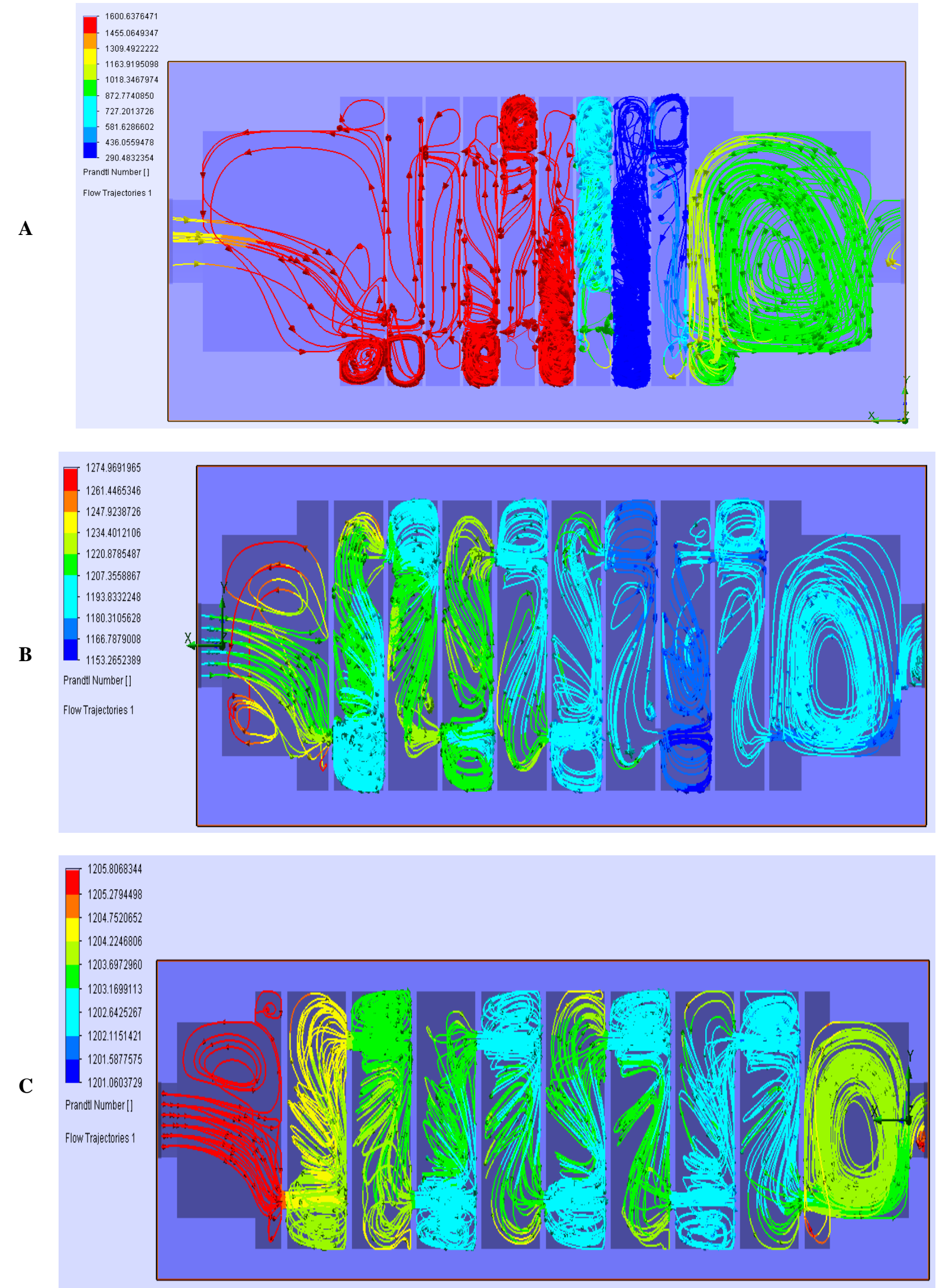

Figure 7 - Prandtl number for working fluid in the first (A), the second (B) and the third (C) models of the packet chokes. 
Working fluid temperature at the inlet differs slightly from working fluid temperature at the outlet, despite temperature changes in the sections of the packet chokes models.

Dynamic viscosity of working fluid in the models of the packet chokes is presented in the Fig. 5 .

Dynamic viscosity of working fluid does not change in $70 \%$ of the sections volumes of the first model of the packet choke at high pressure, and nonNewtonian fluid has the properties of Newtonian fluid. Flow velocities gradient decreases when working fluid pressure decreases. At movement of working fluid from one section to another section through the small diameter orifice are observed the following changes:

1. Dynamic viscosity of working fluid is more before the orifice;

2. Dynamic viscosity of working fluid is less after the orifice;

3. Dynamic viscosity increases at movement of working fluid from the orifice to the next orifice.

Working fluid vorticity in the models of the packet chokes is presented in the Fig. 6 .

Working fluid flow at the inlet is laminar in three models of the packet chokes. Vortices are formed before and after the orifices in the plates of the packet choke. Vortex formation frequency of working fluid flow in the first model of the packet choke is increased in 5 to 7 sections. The orifice diameter in the plates and distance between the plates of the packet choke affect on intensity of vortex flow of working fluid. The more the orifice diameter in the plates and distance between the plates, the less intensity of vortex flow of working fluid.

Changing of Prandtl number [8] for working fluid in the models of the packet chokes is presented in the Fig. 7.

Prandtl number $P_{r}$ is proportional to dynamic viscosity $\eta$ and inversely proportional to the thermal diffusivity coefficient $a=\frac{\lambda}{\rho c_{p}}$.

In the formula, $\lambda$ is thermal conductivity of working fluid, $\rho$ is density of working fluid, $c_{p}$ is isobaric specific heat of working fluid.

Let is to find the maximum and minimum values of the thermal diffusivity coefficient in the conditions of working fluid flow in the first, the second and the third models of the packet chokes.

1. For the first model:

$\eta_{\text {max.1mod. }}=0.138 \mathrm{~Pa} \times \mathrm{s}, \eta_{\text {min.lmod. }}=0.025 \mathrm{~Pa} \times \mathrm{s}$,

$P_{\text {rmax. } 1 \text { mod. }}=1600, P_{\text {rmin. } 1 \text { mod }}=290$.

$a_{\text {max } .1 \mathrm{mod} .}=\frac{\eta_{\max .1 \mathrm{mod} .}}{P_{r \max .1 \mathrm{mod} .}}=\frac{0.138}{1600}=0.8625 \times 10^{-4} \frac{\mathrm{m}^{2}}{\mathrm{~s}}$,

$a_{\text {min.1 mod. }}=\frac{\eta_{\min .1 \mathrm{mod} .}}{P_{r \min .1 \mathrm{mod} .}}=\frac{0.025}{290}=0.8621 \times 10^{-4} \frac{\mathrm{m}^{2}}{\mathrm{~s}}$.

2. For the second model:

$\eta_{\text {max.2mod. }}=0.1099 \mathrm{~Pa} \times \mathrm{s}, \eta_{\text {min.2mod. }}=0.0994 \mathrm{~Pa} \times \mathrm{s}$,

$P_{\text {rmax. } 2 \text { mod. }}=1274, P_{\text {rmin. } 2 \text { mod. }}=1153$.

$a_{\text {max .2 mod. }}=\frac{\eta_{\max .2 \bmod .}}{P_{r \max .2 \bmod .}}=\frac{0.1099}{1274}=0.8626 \times 10^{-4} \frac{\mathrm{m}^{2}}{\mathrm{~s}}$,

$a_{\text {min } .2 \text { mod. }}=\frac{\eta_{\min .2 \mathrm{mod} .}}{P_{r \min .2 \mathrm{mod} .}}=\frac{0.0994}{1153}=0.8621 \times 10^{-4} \frac{\mathrm{m}^{2}}{\mathrm{~s}}$.

3. For the third model:

$\eta_{\text {max.3mod. }}=0.104 \mathrm{~Pa} \times \mathrm{s}, \eta_{\text {min.3mod. }}=0.1036 \mathrm{~Pa} \times \mathrm{s}$,

$P_{\text {rmax.3mod. }}=1205, P_{\text {rmin.3mod. }}=1201$.

$a_{\text {max } .3 \text { mod. }}=\frac{\eta_{\text {max } .3 \bmod .}}{P_{r \text { max } .3 \bmod .}}=\frac{0.104}{1205}=0.8631 \times 10^{-4} \frac{\mathrm{m}^{2}}{\mathrm{~s}}$,

$a_{\text {min. } 3 \bmod .}=\frac{\eta_{\min .3 \bmod .}}{P_{r \min .3 \mathrm{mod} .}}=\frac{0.1036}{1201}=0.8626 \times 10^{-4} \frac{\mathrm{m}^{2}}{\mathrm{~s}}$.

The thermal diffusivity coefficient of working fluid in three models of the packet chokes has almost the same value. Therefore, distance between the plates and the orifice diameter will not affect to the thermal diffusivity coefficient.

\section{Conclusion}

1. The rational internal design of the packet choke is selected under the condition of minimum pressure drop at the inlet and the outlet. These requirements are performed at movement of working fluid in the third model of the packet choke.

2. Inlet pressure and a cross sectional area of the hydraulic resistances affect on viscosity of nonNewtonian fluid.

3. The thermal diffusivity coefficient for all models of the packet chokes is in a numeric range of $0.8621 \times 10^{-4}-0.8631 \times 10^{-4}$. Thus, the internal design of the packet choke does not affect to the thermal diffusivity coefficient. 


\begin{tabular}{l|lr|ll|ll} 
& ISRA (India) & $=\mathbf{1 . 3 4 4}$ & SIS (USA) & $=\mathbf{0 . 9 1 2}$ & ICV (Poland) & $=\mathbf{6 . 6 3 0}$ \\
Impact Factor: & ISI (Dubai, UAE) $=\mathbf{0 . 8 2 9}$ & PUHL (Russia) $=\mathbf{0 . 2 0 7}$ & PIF (India) & $=\mathbf{1 . 9 4 0}$ \\
& GIF (Australia) & $\mathbf{0 . 5 6 4}$ & ESJI (KZ) & $=\mathbf{4 . 1 0 2}$ & IBI (India) & $\mathbf{= 4 . 2 6 0}$ \\
& JIF & $\mathbf{1 . 5 0 0}$ & SJIF (Morocco) $=\mathbf{2 . 0 3 1}$ & & \\
\hline
\end{tabular}

\section{References:}

1. (2010) An Introduction to Flow Analysis Applications with SolidWorks Flow Simulation, Student Guide (2010) Dassault Systèmes - SolidWorks Corporation. 35 p.

2. (2018) Non-Newtonian fluid. Available: https://en.wikipedia.org/wiki/Non-

Newtonian_fluid (Accessed: 14.06.2018).

3. Nguyen QH, Nguyen ND (2012) Incompressible Non-Newtonian Fluid Flows. Continuum Mechanics - Progress in Fundamentals and Engineering Applications. Pp. 47-72.

4. Metzner AB, Reed JC (1955) Flow of nonNewtonian fluids correlation of the laminar, transition, and turbulent-flow regimes. AIChE Journal, 1. Pp. 434-440.
5. (2018) Power-law fluid. Available: https://en.wikipedia.org/wiki/Power-law_fluid (Accessed: 14.06.2018).

6. (2018) Viscosity for Non-Newtonian Fluids. Available:

http://jullio.pe.kr/fluent6.1/help/html/ug/node29 7.htm (Accessed: 14.06.2018).

7. (2018) Black-body radiation. Available: https://en.wikipedia.org/wiki/Blackbody_radiation (Accessed: 14.06.2018).

8. (2018) Prandtl Number. Available: https://www.engineersedge.com/heat transfer/p randtl_number_13954.htm (Accessed: 14.06.2018). 